\title{
Correction to: Prognostic factors of mortality after surgery in infective endocarditis: systematic review and meta-analysis
}

\author{
Laura Varela Barca ${ }^{1}$ (1) - Enrique Navas Elorza ${ }^{2}$. Nuria Fernández-Hidalgo ${ }^{3}$. Jose Luis Moya Mur ${ }^{4}$. \\ Alfonso Muriel García ${ }^{5}$ - B. M. Fernández-Felix ${ }^{5,6}$. Javier Miguelena Hycka ${ }^{1}$ Jorge Rodríguez-Roda ${ }^{1}$. \\ Jose López-Menéndez ${ }^{1}$
}

Published online: 24 September 2019

(c) Springer-Verlag GmbH Germany, part of Springer Nature 2019

\section{Correction to: Infection \\ https://doi.org/10.1007/s15010-019-01338-x}

The original version of this article unfortunately contained a mistake. The spelling of the name "Nuria FernándezHidalgo" was incorrect.

The original article has been corrected.

The original article can be found online at https://doi.org/10.1007/ s15010-019-01338-x.

Laura Varela Barca

lauravarela21089@gmail.com

1 Department of Cardiovascular Surgery, University

Hospital Ramon y Cajal, Ctra. Colmenar Viejo, km. 9.100,

28034 Madrid, Spain

2 Department of Infectology, University Hospital Ramon y Cajal, Madrid, Spain

3 Department of Infectious Diseases, University Hospital Vall d'Hebron, Barcelona, Spain

4 Department of Cardiology, University Hospital Ramon y Cajal, Madrid, Spain

5 Clinical Biostatistics Unit, Hospital Ramon y Cajal (IRYCIS), Madrid, Spain

6 CIBER Epidemiology and Public Health (CIBERESP), Madrid, Spain 